\title{
Caesarean scar endometriosis
}

\author{
Garima Kumari* \\ Department of Obstetrics and Gynecology, SMS Hospital, Jaipur, Rajasthan, India \\ Received: 10 September 2021 \\ Accepted: 05 October 2021 \\ *Correspondence: \\ Garima Kumari, \\ E-mail: garimabagaria22@gmail.com \\ Copyright: (c) the author(s), publisher and licensee Medip Academy. This is an open-access article distributed under \\ the terms of the Creative Commons Attribution Non-Commercial License, which permits unrestricted non-commercial \\ use, distribution, and reproduction in any medium, provided the original work is properly cited.
}

\begin{abstract}
Endometriosis is defined by the presence and growth of ectopic functional endometrial tissue outside the uterus. The symptoms are nonspecific, typically involving abdominal wall pain at the time of menstruation. It commonly follows obstetrical and gynecological surgeries. The diagnosis is frequently made only after excision of scar the diseased tissue. A case report of 34 year old female patient presenting with scar endometriosis 7 years after her last LSCS (lower segment caesarean section). The patient came with the complaint of supra pubic swelling since 6 months, which was growing slowly. Her menstrual history was regular, but she had lower abdominal pain during menstruation. On clinical history, examination and USG finding the swelling was diagnosed as scar endometriosis.
\end{abstract}

Keywords: Endometriosis, Abdominal scar, LSCS and prevention

\section{INTRODUCTION}

Endometriosis is defined as the presence of endometrial glands and stroma outside the uterus. It affects $10-15 \%$ of all women of reproductive age, that is, $18-45$ years. ${ }^{1,2}$ Scar endometriosis is reported in only $0.03-0.15 \%$ of all cases of endometriosis, often resulting in debilitating pain and infertility. Although most frequently found in the pelvis, reports citing extrapelvic endometrial locations range from the lungs to the extremities. ${ }^{3}$ Incisional or scar endometriosis has also been described, however, with a much rarer incidence (fewer than $1 \%$ of affected patients).,5 This entity can result in unnecessary procedures, delayed or misdiagnosis and can cause emotional and physical distress to the patient. The present study described a case of scar endometriosis and reviewed the literature to elucidate physical signs and symptoms that may lead to earlier diagnosis and prompt treatment.

\section{CASE REPORT}

A 34 year old woman was seen in consultation for a painful abdominal scar. She was an otherwise healthy woman with no significant medical history. Her surgical history included an uncomplicated caesarean section three years previously. She complained of increasing pain and tenderness at the Pfannenstiel incisional site but did not report any cyclical pattern associated with these symptoms. Physical examination revealed a well-healed caesarean scar, with a nonmobile, nodular, moderately pigmented area at its lateral border. Exquisite point tenderness to palpation over the nodular area was noted. On USG finding the swelling was diagnosed as scar endometriosis and the patient was taken to the operating room for exploration of the abdominal wound and excision.

Intraoperatively, extensive fibrosis of the scar to the fascia was noted. The scar was completely excised with the nodular portion, and the specimen was sent to the pathology department (Figure 1). The final report revealed dermal fibrosis with endometriosis. The patient's postoperative course was uneventful and her pain subsided.

\section{Pathology}

Endometriosis is defined by occurrence of endometriallike epithelium and stroma outside the uterine cavity. This condition is commonly seen in females of reproductive 
age. Grossly, endometriosis may present as small, dark red, black or bluish cysts or nodules on the surface of peritoneal and pelvic organs. Histologically, endometriosis is characterized by the ectopic presence of endometrial-like glands, spindled endometrial stroma and hemosiderin deposition either within the macrophages or in the stroma (Figure 2). In many cases, this diagnostic triad was not present or the glands and stroma may be obscured by haemorrhage, foamy cells and hemosiderinladen macrophages. When this occured, the diagnosis may be suggested but histological confirmation may not be possible.

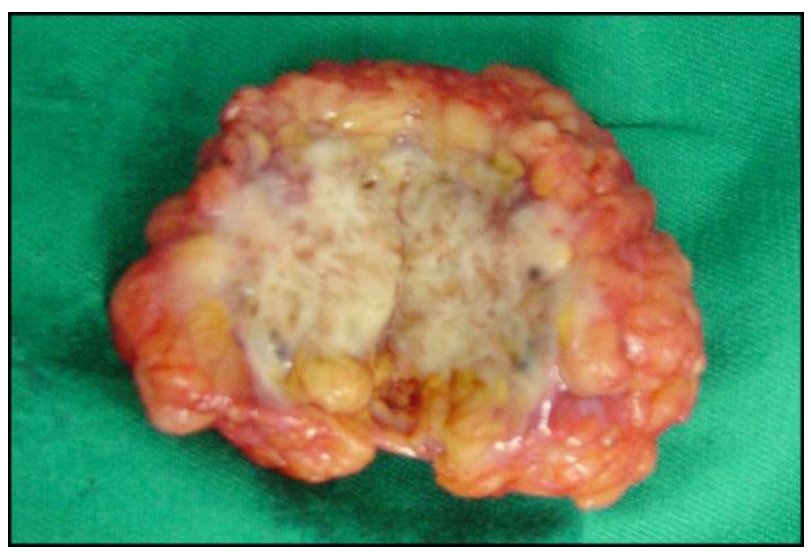

Figure 1: The specimen of scar endometriosis.

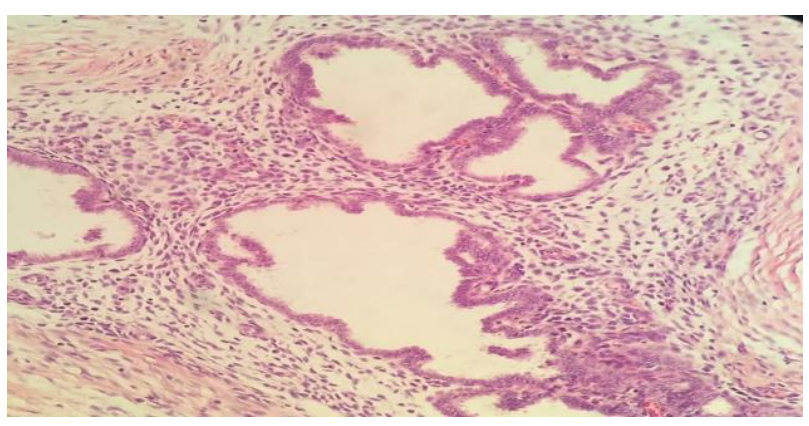

Figure 2: Histopathology of scar endometriosis.

\section{DISCUSSION}

Scar endometriosis is a rare entity reported in the gynecological literature and presents in women who have undergone a previous abdominal or pelvic operation. ${ }^{6}$ The incidence had been estimated to be only $0.03 \%$ to $0.15 \%$ of all cases of endometriosis. ${ }^{4,5}$ Many theories as to the cause of scar endometriosis have been postulated; however, the most generally accepted theory was the iatrogenic transplantation of endometrial implants to the wound edge during an abdominal or pelvic surgery. ${ }^{4,5,7,8}$

The diagnosis of scar endometriosis may be challenging. Cyclical changes in the intensity of pain and size of the endometrial implants during menstruation were usually characteristic of classical endometriosis. However, in the largest reported series to date, only $20 \%$ of the patients exhibited these symptoms. ${ }^{9}$ Patients usually complained of tenderness to palpation and a raised, unsightly hypertrophic scar.

Management included both surgical excision and hormonal suppression. ${ }^{3,10}$ Oral contraceptives, pregestational and androgenic agents have been tried. It was believed that hormonal suppression was only partially effective and surgical excision of the scar was the definitive treatment. ${ }^{10,11}$

Scar endometriosis is a rare and often elusive diagnosis that can lead to both patient and physician frustration. One should maintain a high level of suspicion in any woman presenting with pain at an incisional site, most commonly following pelvic surgery. A thorough history and physical examination should always be performed and every surgeon should consider this entity in their differential diagnosis.

\section{CONCLUSION}

Endometriosis is a debilitating disease that impacts the quality of life of adolescent and adult patients. Delayed diagnosis is common and may lead to a decline in reproductive potential and fertility. A semi or non-invasive diagnostic biomarker would be a useful tool to identify patients early in the disease process and thus improving outcomes including less pain and better fertility. The occurrence of abdominal wall scar endometriosis after caesarean section has been a definite entity; steps to prevent this complication have not been explained. Literature recommends that through cleaning, irrigation with saline and closure of abdominal wound will prevent scar endometriosis.

Funding: No funding sources

Conflict of interest: None declared

Ethical approval: Not required

\section{REFERENCES}

1. American College of Obstetricians and Gynecologists. Practice bulletin no. 114: management of endometriosis. Obstet Gynecol. 2010;116(1):22336.

2. Bektaş H, Bilsel Y, Sari YS, Ersöz F, Oğuz Koç O, Mehdi Deniz M, et al. Abdominal wall endometrioma; a 10-year experience and brief review of the literature. J Surg Res. 2010;164(1):77-81.

3. Wolf G, Singh K. Cesarean scar endometriosis: a review. Obstet Gynecol Surv. 1989;44(2):89-95.

4. Francica G, Giardiello C, Angelone G, Cristiano S, Finelli R, Tramontano G. Abdominal wall endometriosis near cesarean delivery scars. J Ultrasound Med. 2003:22(10):1041-7.

5. Kaloo P, Reid G, Wong F. Caesarean section scar endometriosis: two cases of recurrent disease and a literature review. Aust NZ J Obstet Gynaecol. 2002;42:218-20. 
6. Mistrangelo M, Gilbo N, Cassoni P. Surgical scar endometriosis. Surg Today. 2014;44(4):767-72.

7. Khoo JJ. Scar endometriosis presenting as an acute abdomen: a case report. Aust NZ Obstet Gynaecol. 2003;43(2):164-5.

8. Tanos B, Anteby SO. Caesarean scar endometriosis. Int J Gynaecol Obstet. 1994;47(2):163-6.

9. Douglas C, Rotimi O. Extragenital endometriosis: a clinicopathological review of Glasgow hospital with case illustrations. J Obstet Gynaecol. 2004;24(7):8048.
10. Ding CD, Hsu S. Scar endometriosis at the site of cesarean section. Taiwanese J Obstet Gynecol. 2006;45(3):247-9.

11. Schoelefield HJ, Sajjad Y, Morgan PR. Cutaneous endometriosis and its association with caesarean section and gynaecological procedures. J Obstet Gynaecol. 2002;22(5):553-4.

12. Wasfie T, Gomez E, Seon S, Zado B. Abdominal wall endometrioma after cesarean section: a preventable complication. Int Surg. 2002;87(3):175-7.

Cite this article as: Kumari G. Caesarean scar endometriosis. Int J Reprod Contracept Obstet Gynecol 2021;10:4331-3. 